ORIGINAL ARTICLE

\title{
Mental Disorder in Obesity
}

\author{
MAHESA PERMANA KARDIS ${ }^{1}$, ALIFIATI FITRIKASARI ${ }^{2}$ \\ ${ }^{1}$ Department of Psychiatry, Dr. Kariadi Hospital, Semarang, Indonesia \\ ${ }^{2}$ Department of Psychiatry, Faculty of Medicine, Diponegoro University, Semarang, Indonesia \\ Corresponding author: Alifiati Fitrikasari, email: fitrisutomo@yahoo.com, telp: +628122908847
}

\begin{abstract}
Background: Obesity is a condition of incompatibility between body weight and height that shows a value above the normal range of body mass index. Obesity has an impact on the individual's psychological developmental processes. Limitations of Research on the relationship between obesity and mental disorders lead researchers to be interested in knowing whether there are incidents and types of mental disorders in obese individuals.

Objective: To investigate mental disorders in individual with obesity.

Methods: This was an observational and cross-sectional study. A total of 45 respondents who met the inclusion criteria according to WHO Asia Pacific obesity criteria (BMI $\geq 25 \mathrm{Kg} / \mathrm{m} 2$ ) were screened using MINI ICD 10. Statistical analysis using Mann-Whitney Test and Fisher's Exact Test to determine the relationship of mental disorders incident with the demographic characteristics of respondents. Gamma and Mann-Whitney tests were used to determine the relationship between mental disorders types with the demographic characteristics of respondents.

Results: There were eight of 45 respondents experiencing mental disorders. The study found that three respondents were diagnosed with general anxiety disorder, three with depression, one with distimia, and one with mania at past. There was no significant relationship between mental disorders incidents and demographic characteristics. The relationship between types of mental disorders with a history of mental disorders in the nuclear family showed significant results.

Conclusion: There were mental disorders in obese individuals. Most mental disorders diagnosis were depression and general anxiety disorder.

Keywords: Obesity, Mental disorder
\end{abstract}

\section{INTRODUCTION}

Obesity is an increase in body weight that exceeds the limits of physical and skeletal needs, leading to excessive accumulation of body fat. Obesity is a complex disease, resulting from a combination of genetic vulnerability, increased intake of high-energy foods, and decrease in the need for physical activity. Prevalence of obesity has reached epidemic proportions in industrialized countries and now considered to be the main cause of death so that many prevention efforts are carried out in these countries. ${ }^{1}$ According to WHO statistics in 2015 shows the percentage of adult obesity ( $\geq 18$ years) which is quite high in many countries with more women than men. ${ }^{2}$ Obesity basically refers to excess fat in the body. In healthy people, body fat accounts for around 25 percent of body weight in women and 18 percent in men. Large muscle mass or someone who has a normal body weight but has high body fat is not included of obesity. Body Mass Index (BMI) is an assessment index to measure obesity. BMI is calculated by dividing the weight in kilograms by the height in meters squared $\left(\mathrm{Kg} / \mathrm{m}^{2}\right)$. Mental conditions play a role in the development of obesity, but the mechanism is definitely not yet known. Similarly, obesity is a factor that affects the mental state. Researchers have suggested that certain family history, trigger factors, personality structure, or unconscious conflict as factors that affect obesity, on the contrary, people who are overweight may be the background of psychiatric disorders. Hyperphagia is one of the coping mechanisms that is often used by obese individuals. $^{1}$

The tendency to maintain weight after the process of action on the stomach experiences failure after a 5-year follow-up. ${ }^{3}$ A study conducted on obese adolescents who were followed for 5 years to young adulthood (>18 years) showed a high number of BMl values compared to developing non-obese. ${ }^{4}$ In addition, other studies say that families who are obese and cardiometabolic disease positively show a significant incidence of obesity, especially in the pre-puberty age group. ${ }^{5}$

In Indonesia, there are still not enough studies that link obesity with mental disorders in adults. Based on this, researchers are interested to examine the conditions in obese individuals who experience mental disorders and also the types of mental disorders that occur. The aim of this study is whether the incident and the type of mental disorder in obesity person.

\section{MATERIAL AND METHODS}

Study design is observational with cross sectional. The research conducted was at Diponegoro University in October until November 2018.

Subjects: The sample population was undergraduate students at Diponegoro University, with a minimum sample of 45 people.

Data Collection and Analysis: Inclusion criteria were students college who are willing to take part of research and sign up for informed consent, also meet criteria obesity $\geq 25 \mathrm{Kg} / \mathrm{m}^{2}$ using WHO Asian Pasific. ${ }^{6}$ Respondents who met the inclusion criteria were screened for mental disorders using Mini International Neuropsychiatry Interview (MINI) ICD 10.7 Data from demographic respondents and MINI ICD 10 screening were analyzed using statistical data processing program. Relationship between demographic respondents and incidents mental disorders were analyzed using Mann-Whitney test and Fisher's Exact Test. Relationship between demographic 
respondents and mental disorders types were analyzed using Gamma test and Mann-Whitney test. The limit for statistical significance was set at $p<0.05(95 \%$ degree of trust).

Ethical Clearance: Ethical approval for this study was obtained from ethical research committee at Faculty of Medicine, Diponegoro University and Kariadi Central General Hospital (ethical clearance number is No.427/EC/FK-RSDK/VII/2018).

\section{RESULTS}

From 45 obtained 8 respondents met MINI ICD 10 criteria of mental disorder (Table 1). The most respondents are at age 19 years and also the most acquired mental disorders. Obesity is also more common in women so that mental disorders also occur in women. Respondents with a history of the nuclear family with diabetes mellitus and mental disorders detected showed fewer results. Obese respondents who detected mental disorders and had a history of mental disorders in the nuclear family were found in 1 respondent. While those who are obese for more than 5 years show higher rates of mental disorders. There is no significant relationship between the incidence of mental disorders and the characteristics of the respondents (Table 2). Bivariate variables were tested between types of mental disorders with the characteristics of the respondents (Table 3). Types of mental disorders had a significant relationship with a family history of mental disorders $(p=0.028)$.

Tabel 1. Characteristic respondent

\begin{tabular}{|c|c|c|c|}
\hline Variable & Total & $\begin{array}{c}\text { Persentage } \\
(\%)\end{array}$ & $\begin{array}{c}\text { Mental disorder } \\
\text { (total (\%)) }\end{array}$ \\
\hline Age & & & $4(50 \%)$ \\
\hline 19 & 32 & 71,1 & $3(37,5 \%)$ \\
\hline 20 & 9 & 20 & $1(12,5 \%)$ \\
\hline 21 & 4 & 8,9 & $3(37,5 \%)$ \\
\hline Gender & & 31,1 & $5(62,5 \%)$ \\
\hline Male & 14 & 68,9 & \\
\hline Female & 31 & 60 & $5(62,5 \%)$ \\
\hline History of nuclear family obesity
\end{tabular}

\begin{tabular}{|c|c|c|c|}
\hline No & 18 & 40 & $3(37,5 \%)$ \\
\hline \multicolumn{4}{|c|}{ History of nuclear family DM } \\
\hline Yes & 21 & 46,7 & $2(25 \%)$ \\
\hline No & 24 & 53,3 & $6(75 \%)$ \\
\hline \multicolumn{4}{|c|}{ History of nuclear family mental disorder } \\
\hline Yes & 1 & 2,2 & $1(12,5 \%)$ \\
\hline No & 44 & 97,8 & $7(87,5 \%)$ \\
\hline \multicolumn{4}{|c|}{ Years of conditions } \\
\hline$<5$ years & 11 & 24,4 & $3(37,5 \%)$ \\
\hline$>5$ years & 34 & 75,6 & $5(62,5 \%)$ \\
\hline
\end{tabular}

Table 2. Variable test mental disoders incident and respondent characteristics

\begin{tabular}{|c|c|c|c|c|c|c|}
\hline & \multicolumn{4}{|c|}{ Mental Disorders } & \multirow{3}{*}{$\begin{array}{c}\text { Total } \\
\mathbf{n}\end{array}$} & \multirow{3}{*}{$\begin{array}{c}\mathbf{P} \\
\text { value }\end{array}$} \\
\hline & \multicolumn{2}{|r|}{ Yes } & \multicolumn{2}{|c|}{ No } & & \\
\hline & $\mathbf{N}$ & $\%$ & $\mathbf{N}$ & $\%$ & & \\
\hline \multicolumn{6}{|l|}{ Age } & \multirow{5}{*}{$0,173^{*}$} \\
\hline 19 & 4 & $50 \%$ & 28 & $75,7 \%$ & 32 & \\
\hline 20 & 3 & $37,5 \%$ & 6 & $16,2 \%$ & 9 & \\
\hline 21 & 1 & $12,5 \%$ & 3 & $8,1 \%$ & 4 & \\
\hline Total & 8 & $17,8 \%$ & 37 & $82,2 \%$ & & \\
\hline \multicolumn{6}{|l|}{ Gender } & \multirow{4}{*}{$\underset{*}{0,689}$} \\
\hline - $\quad$ Male & 3 & $21,4 \%$ & 11 & $78,6 \%$ & 14 & \\
\hline Female & 5 & $16,1 \%$ & 26 & $83,9 \%$ & 31 & \\
\hline Total & 8 & $17,8 \%$ & 37 & $82,2 \%$ & & \\
\hline \multicolumn{6}{|c|}{ History of nuclear family obesity } & \multirow{4}{*}{$\underset{*}{1,000^{*}}$} \\
\hline - $\quad$ Yes & 5 & $18,5 \%$ & 22 & $81,5 \%$ & 27 & \\
\hline No & 3 & $16,7 \%$ & 15 & $83,3 \%$ & 18 & \\
\hline Total & 8 & $17,8 \%$ & 37 & $82,2 \%$ & & \\
\hline \multicolumn{6}{|c|}{ History of nuclear family DM } & \multirow{4}{*}{$\underset{*}{0,059 *}$} \\
\hline - $\quad$ Yes & 1 & $5 \%$ & 19 & $95,0 \%$ & 20 & \\
\hline - $\quad$ No & 7 & $28 \%$ & 18 & $72,0 \%$ & 25 & \\
\hline Total & 8 & $17,8 \%$ & 37 & $82,2 \%$ & & \\
\hline \multicolumn{6}{|c|}{ History of nuclear family mental disorder } & \multirow{4}{*}{$\underset{*}{0,178^{*}}$} \\
\hline - $\quad$ Yes & 1 & $100 \%$ & 0 & $0 \%$ & 1 & \\
\hline No & 7 & $15,9 \%$ & 37 & $84,1 \%$ & 44 & \\
\hline Total & 8 & $17,8 \%$ & 37 & $82,2 \%$ & & \\
\hline \multicolumn{6}{|c|}{ Years of conditions } & \multirow{4}{*}{$\underset{*}{0,382^{*}}$} \\
\hline - $\quad<5$ years & 3 & $27,3 \%$ & 8 & $72,7 \%$ & 11 & \\
\hline$>5$ years & 5 & $14,7 \%$ & 29 & $85,3 \%$ & 34 & \\
\hline Total & 8 & $17,8 \%$ & 37 & $82,2 \%$ & & \\
\hline
\end{tabular}

Annotation: significant $\mathrm{p}<0,05$ (2-tailed); * Mann-Whitney; * Fisher's Exact

Table 3. Variable test mental disorder type and respondent characteristics

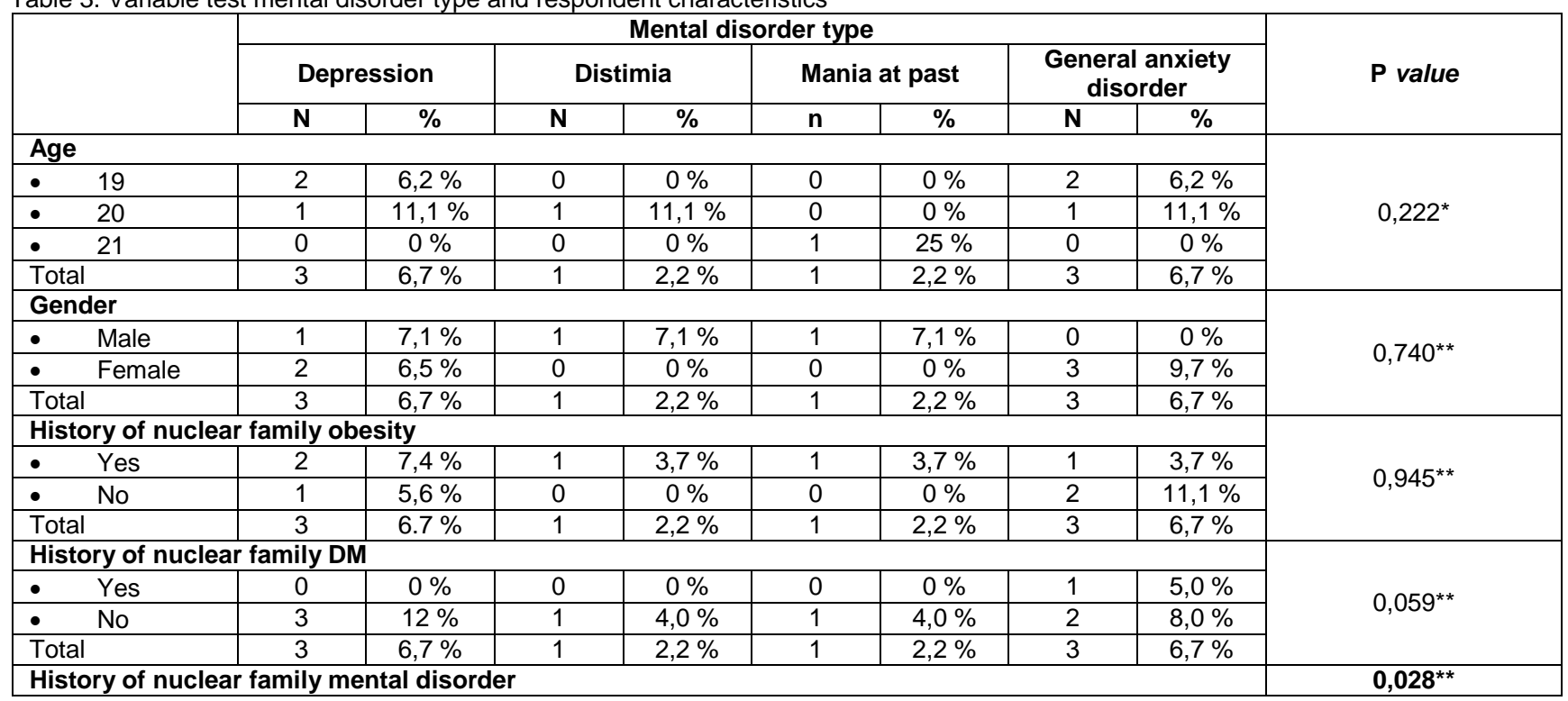




\begin{tabular}{|c|c|c|c|c|c|c|c|c|c|}
\hline Yes & 0 & $0 \%$ & 0 & $0 \%$ & 1 & $100 \%$ & 0 & $0 \%$ & \\
\hline No & 3 & $6,8 \%$ & 1 & $2,3 \%$ & 0 & $0 \%$ & 3 & $6,8 \%$ & \\
\hline Total & 3 & $6,7 \%$ & 1 & $2,2 \%$ & 1 & $2,2 \%$ & 3 & $6,7 \%$ & \\
\hline \multicolumn{9}{|c|}{ Years of conditions } & \multirow{4}{*}{$0,303^{* *}$} \\
\hline - $\quad<5$ tahun & 1 & $9,1 \%$ & 0 & $0 \%$ & 0 & $0 \%$ & 2 & $18,2 \%$ & \\
\hline - $\quad>5$ tahun & 2 & $5,9 \%$ & 1 & $2,9 \%$ & 1 & $2,9 \%$ & 1 & $2,9 \%$ & \\
\hline Total & 3 & $6,7 \%$ & 1 & $2,2 \%$ & 1 & $2,2 \%$ & 3 & $6,7 \%$ & \\
\hline
\end{tabular}

Annotation: significant $p<0,05$ (2-tailed); * Gamma; ** Mann-Whitney

\section{DISCUSSION}

From total 45 people respondents were screened for mental disorders using the MINI ICD and found that 8 people (17.8\%) met the criteria for mental disorders, and 8 people who have mental disorders, 5 of them are women. Research conducted by Svetlana, et al. (2013), showed a higher risk of female mental disorders due to having a lower level of education than men, especially in younger age women, easily exposed to stressors, especially in young women who work because a more complex role in daily life such as a mother and wife, besides that hormonal conditions in women tend to fluctuate compared to men. ${ }^{8}$ In this study, the education level of the respondents was equivalent, but mental disorders were more often obtained at the youngest age so that it was more easily exposed to stressors, especially to activities in the early years of lectures.

Obesity in women will affect biological, behavioral, and social factors that increase the risk factors for mental disorders. Based on the most probable underlying biological factors, the number of adipose tissue in women is more than that of men, so it triggers more and more peripheral digestive hormones and enzymes, and if in a chronic condition the central nervous system will affect the HPA axis regulation which can trigger emotional disturbances. ${ }^{9}$ Psychological and social factors in obese women have a tendency in terms of perceptions of selfimage that are lacking compared to someone who has a normal weight, besides that norms and culture can affect an obese woman in limiting each of her activities. ${ }^{10}$ In this study, obese women are more than to men, and this was directly proportional to the number of mental disorders detected. Various things in the development of today's social life of women cause demands in themselves to look better in physical terms. Social demands on women influence the perception of low self-image, and if this continues it causes a psychosocial stressor which can subsequently result in an influence on psychiatric conditions.

Respondents who experienced mania when they were known to have a family history of mental disorders. According to Ozdemir et al (2016), it was revealed that there was a significant relationship between parents who experienced mental disorders to children who experienced mood disorders. ${ }^{11}$

The types of mental disorders that occur more are depression and overall anxiety disorders. Based on research conducted by AIQahtani et al (2015), said that depression and anxiety disorders are the most common in students who have excess body weight. ${ }^{12}$ Nigatu et al (2015), obesity after being followed for 2 years showed significant symptoms of depression. Another conclusion that there was no significant relationship when depression followed for 2 years showed signs of increasing weight to obesity. ${ }^{13}$

Biological factors of obesity which can cause mental disorders are high levels of leptin in obesity correlated with low cortisol levels, and in response to staying balanced, ACTH production will be increased. However, the condition of high levels of leptin that continues to occur causes the level of cortisol to become fluctuating so that if in a chronic there will be dysregulation of HPA axis, and result is the occurrence of emotional disorders. ${ }^{14}$

First limitations this study, respondents are not specifically grouped such as age range, place of residence or from certain socioeconomic groups. Second limitation, does not exclude the underlying factors of obesity such as hormonal disorders and use of drugs related to obesity.

\section{CONCLUSION}

In accordance with the research hypothesis that there are mental disorders in obese individuals. The most types of mental disorders are overall anxiety disorders and depression.

Acknowledgements: This research was funded by Research Development of Faculty of Medicine, Diponegoro University, Indonesia.

\section{REFERENCES}

1. Sadock, Benjamin James; Sadock VA. Synopsis kaplan 10th. In: kaplan \& sadock's synopsis of psychiatry: behavioral Sciences/Clinical Psychiatry. 10th edition. Lippincott Williams \& Wilkins Inc; 2007:741.

2. World Health Organization. World Health Statistics 2015.; 2015

3. Ulen CG, Huizinga MM, Beech B, Elasy TA. Weight regain prevention. Res Clin Pract. 2012.26;3

4. Gordon-Larsen P, Adair LS, Nelson MC, Popkin B. Five-year obesity incidence in the transition period between adolescence and adulthood: the national longitudinal study of adolescent health. Am J Clin Nutr. 2012.80;569-575.

5. Corica D, Aversaa T, Valezise M, Messina MF. Does family history of obesity, cardiovascular, and metabolic diseases influence onset and severity of childhood obesity? Front Endocrinol. 2018:9;187.

6. Basset $\mathrm{J}$, Inoue $\mathrm{S}$, Zimmet $\mathrm{P}$, Caterson I, Chunming $\mathrm{C}$, Ikeda $Y$, et al. The Asia-Pasific perspective: redifining obesity and its treatment. World Health Organization - West Pasific Region. 2000:18

7. Sheehan D, Janavs J, Maramis A, Lecrubier $Y$, Weiller E, Hergueta $\mathrm{T}$, et al. MINI ICD-10 versi Indonesia. yayasan depresi Indonesia. 2007;2.

8. Svetlana K, Harhaji S, Vesna MJ, Ivana R. Gender differences in mental health among adult populations in Vojvodina, Serbia. Iran J Public Health. 2013:42;8;833-41.

9. Odeniyi IA, Fasanmade OA, Ogbera AO, Ohwovoriole AE. Body mass index and its effect on serum cortisol level. Niger J Clin Pract. 2015;18(2):194-197. 
10. Veggi $A B$, Lopes CS, Sichieri R. Body mass index, body weight perception and common mental disorders among university employees in Rio de Janeiro. Rev Bras Psiquiatr. 2014;26(4):242.

11. Ozdemir O, et al. Family History in Patients with Bipolar Disorder. Turkish Association of Neuropsychiatry in Arch Neuropsychiatry. 2016; 53: 276-279.

12. Alqahtani AAA, Nahar S, Alahmari SM, Alqahtani KSA. Association between obesity and mental disorders among male students of King Khalid University, Abha, Saudi Arabia.
Saudi J Obesity Published by Wolters Kluwer - Medknow. 2015;3(2).

13. Nigatu $Y T$, Bültmann $U$, Reijneveld SA. The prospective association between obesity and major depression in the general population: does single or recurrent episode matter. BMC Public Health. 2015;15:350.

14. Rutters F, La Fleur S, Lemmens S, Born J, Martens M, Adam T. The Hypothalamic-Pituitary-Adrenal Axis, Obesity, and Chronic Stress Exposure: Foods and HPA Axis. Current Obesity Report. 2012;1(4):199-207. 